Jose M. Carnate, Jr., MD²

'Department of Laboratories,

University of the Philippines

Philippine General Hospital

${ }^{2}$ Department of Pathology,

University of the Philippines College of Medicine

Philippine General Hospital
Correspondence: Dr. Jose M. Carnate Jr., Department of Pathology

College of Medicine, University of the Philippines Manila 547 Pedro Gil St., Ermita, Manila 1000

Philippines

Phone (632) 5264450

Telefax (632) 4003638

Email:jmcjpath@yahoo.com

Reprints will not be available from the authors.

The authors declared that this represents original material that is not being considered for publication or has not been published or accepted for publication elsewhere, in full or in part, in print or electronic media; that the manuscript has been read and approved by the authors, that the requirements for authorship have been met by the authors, and that the authors believe that the manuscript represents honest work.

Disclosures: The authors signed disclosures that there are no financial or other (including personal) relationships, intellectual passion, political or religious beliefs, and institutional affiliations that might lead to a conflict of interest.
A 58-year-old Filipino man with a two-year history of a left external auditory canal mass associated with ipsilateral hearing loss underwent polypectomy for a clinical impression of aural polyp.

We received several cream tan, irregular tissue fragments with an aggregate diameter of $1.4 \mathrm{~cm}$. Histopathologic examination shows clusters of tumor cells forming variably sized ducts and glands some of which are cystically dilated; many of these structures have irregular lumina. (Figure 1) Higher magnification shows a dual cell population: an outer layer of round to ovoid cells with clear cytoplasm corresponding to basal myoepithelial cells; and an inner layer of cuboidal to columnar cells that have eosinophilic and granular cytoplasm with decapitating apical ends, corresponding to luminal epithelial cells with apocrine morphology. (Figure 2) Nuclear pleomorphism is mild to moderate, nucleoli are not prominent and mitoses, perineural invasion and necrosis are not seen. In some glands a yellow to golden brown, coarse pigment is seen at the cytoplasm of the luminal cells. (Figure 3) The tumor does not involve the epidermis and there is a variable amount of chronic inflammation. (Figure 4) Based on these features we diagnosed it as ceruminous adenoma.

Ceruminous neoplasms are uncommon tumors found in the external auditory canal. Benign ceruminous tumors include ceruminous adenoma, ceruminous pleomorphic adenoma and ceruminous syringocystadenoma papilliferum. 'Most common among these is the ceruminous adenoma; making up $88 \%$ in one thirty-year review of benign ceruminous neoplasms.' These tumors occur in a wide age range, most commonly in the sixth decade, and have no sex

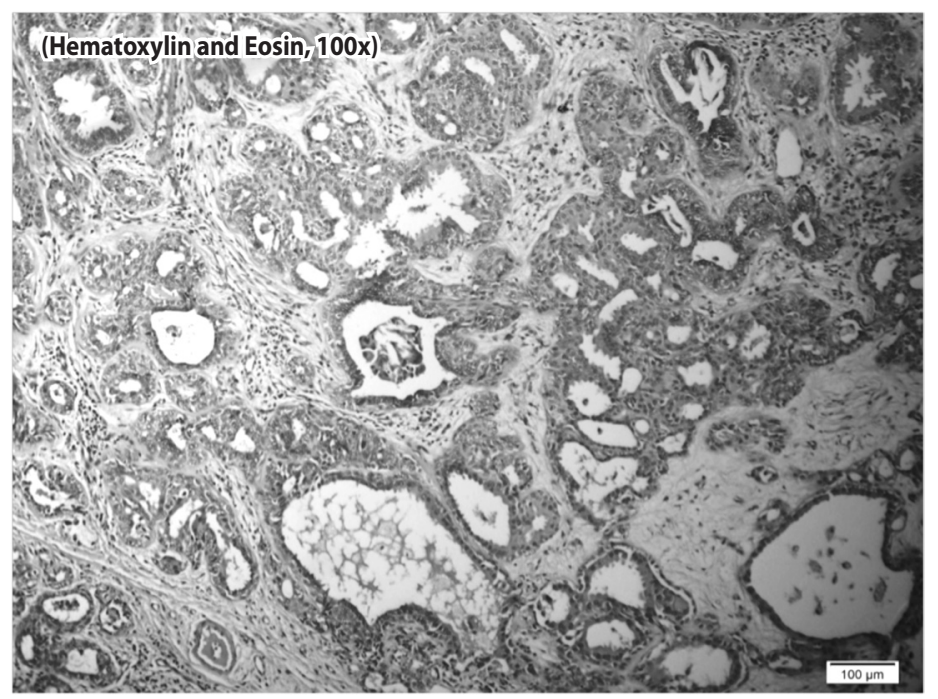

Figure 1. Hematoxylin and Eosin (100x) Neoplastic cells with a glandular and cystic architecture. 


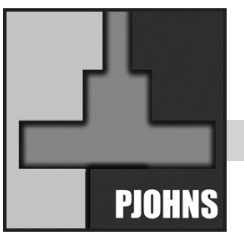

\section{UNDER THE MICROSCOPE}

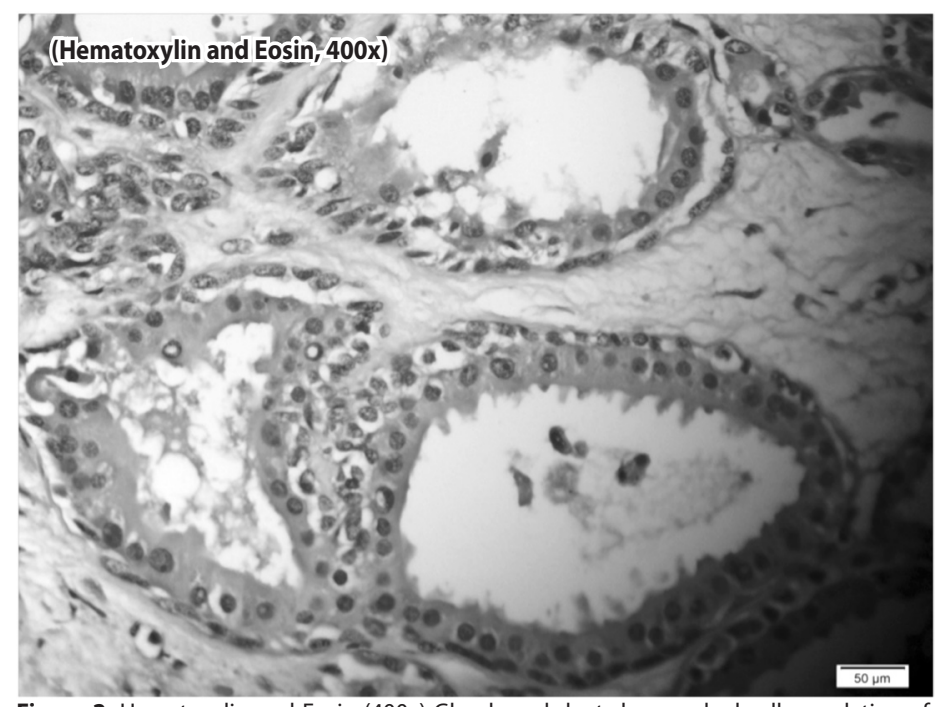

Figure 2. Hematoxylin and Eosin (400x) Glands and ducts have a dual cell population of basal myoepithelial cells and luminal epithelial cells with apocrine features.

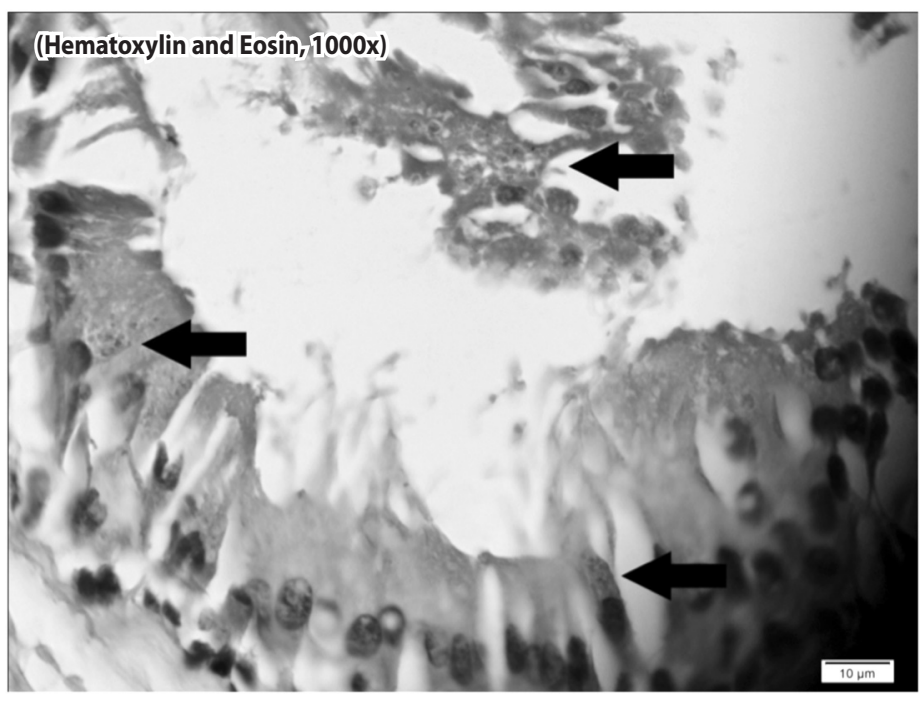

Figure 3. Hematoxylin and Eosin (1000x) Yellow to golden brown, granular "ceroid" material present in cytoplasm of the luminal epithelial cells (marked by black arrows).

predilection. ${ }^{2}$ They present as masses in the outer half of the external auditory canal with hearing changes and pain. ${ }^{2}$ They can be mistaken for aural polyps especially when there is associated chronic suppurative otitis media. ${ }^{3}$

Ceruminous adenomas arise from ceruminous glands ${ }^{4}$ which are modified sweat glands of the outer one half of the external auditory canal.' These are well-circumscribed tumors with glandular architecture composed of two populations of cells with apocrine features as described above. Two microscopic features reinforce the ceruminous nature of the glands: the apocrine morphology and presence of "ceroid" material which are lipofuscin-like pigment granules seen in the cytoplasm of ceruminous gland luminal cells. ${ }^{1,2}$ Both are evident

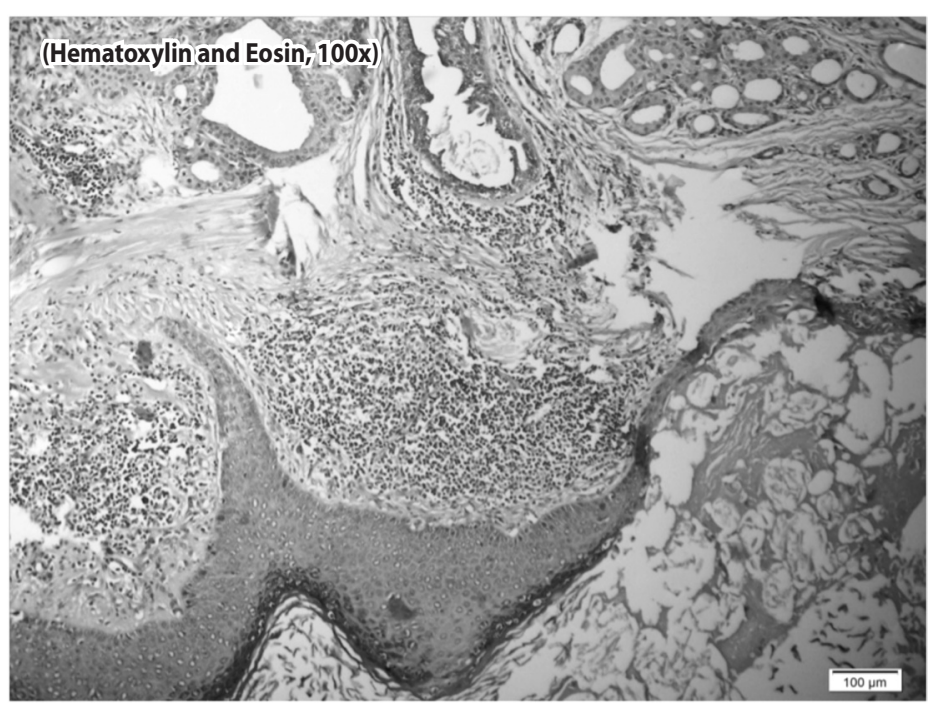

Figure 4. Hematoxylin and Eosin (100x) Chronic inflammation is variably present, sometimes peritumorally. The tumor does not involve the skin.

in our case. The main differential diagnosis of ceruminous adenoma is a ceruminous adenocarcinoma. ${ }^{1,2,5,6}$ Marked pleomorphism, brisk mitoses, necrosis, invasion (e.g. perineural), and loss of the two-cell population favor a diagnosis of ceruminous adenocarcinoma but some well-differentiated cases can be confused with an adenoma. In these cases, sometimes the only clue of malignancy is invasion especially at the surgical margins. ${ }^{6}$ Lassaletta et al..$^{5}$ stressed the importance of adequate tumor excision for a more accurate diagnosis. The presence of a dual cell population and the absence of malignant features led us to a diagnosis of ceruminous adenoma. Immunohistochemical staining for cytokeratin (specifically CK7) which highlight the luminal cells and for basal/myoepithelial cell markers like CK 5/6, S-100 and p63 may be done to further demonstrate the dual cell population. ${ }^{2}$ Complete or adequate local excision is the treatment of choice; however, residual tumor often remains because of the difficulty of surgery at this location leading to recurrence. Subsequent repeat surgery to completely remove the tumor leads to cure. ${ }^{1,2,6}$

\footnotetext{
REFERENCES

1. Thompson LDR, Nelson BL, Barnes EL. Ceruminous adenomas: a clinicopathologic study of 41 cases with a review of literature. Am J Surg Pathol. 2004 Mar; 28(3):308-318.

2. Thompson LDR. In: Thompson LDR, editor. Foundations in Diagnostic Pathology. Head and Neck Pathology. Philadelphia, PA: Elsevier, Inc.; 2006. p.397-340.

3. Srivalli M, Qaiyum HA, Moorthy PNS, Srikanth K. Adenomatous neoplasia presenting as aura polyp. Indian J Otolaryngol Head Neck Surg. 2012 Jan-Mar; 64(1):87-89. DOI: 10.1007/s12070 011-0128-7.

4. Michaels L, Thompson LDR. In: Barnes L, Eveson JW, Reichart P, Sidransky D, editors. World Health Organization Classification of Tumours. Pathology and Genetics of Head and Neck Tumours. 2005; Lyon: IARC Press. p.331.

5. Lassaletta L, Patron M, Oloriz J, Perez R, Gavilan J. Avoiding misdiagnosis in ceruminous gland tumours. Auris Nasus Larynx. 2003 Aug; 30(3):287-290. DOI: 10.1016/S0385-8146(03)00055-5.

6. Gnepp DR. Diagnostic Surgical Pathology of the Head and Neck. $2^{\text {nd }}$ edition. Philadelphia, PA: Saunders; 2009.
} 